\title{
Primary allergy to monocomponent porcine insulin
}

\author{
Piang Kian 'Yap
}

Klinik Soong, Yap and Chong, 115, Jalan SS 2/24, Petaling Jaya, W. Malaysia

\begin{abstract}
Summary: An allergic reaction, occurring in a patient who has been put on monocomponent insulin for the first time, is extremely rare. A case of primary allergy to monocomponent porcine insulin, and its subsequent management, is described here.
\end{abstract}

\section{Case report}

A 32 year old Chinese woman developed gestational diabetes during the fourth month of her pregnancy. Her past medical history was unremarkable. In particular, there was no history of allergy to food or drugs, or family history of atopy or diabetes. She had been a vegetarian for the past $3 \mathrm{y}$ but before this, had consumed all varieties of meat, including pork.

She was treated with Actrapid and Monotard porcine insulin (Novo) once daily. Twelve days after the first injection, she noticed red, itchy and painful lesions at the sites of injections given $2 \mathrm{~d}$ previously. These lesions took another $2 \mathrm{~d}$ to subside. The interval between the injections and the onset of the lesions gradually became shorter, and 1 month later, the reaction would occur within 10 to $15 \mathrm{~min}$ of the injection. Her normal injection site was the thighs; she had tried to switch to the abdomen, but the reactions had also occurred there, though they were less severe. During this period, her blood sugars ranged from $3.9 \mathrm{mmol} / 1$ fasting to $8.9 \mathrm{mmol} / \mathrm{l}$ after meals. One episode of hypoglycaemia was reported.

\section{Immunological studies}

Skin testing was carried out using the Insulin Allergy Testing Kit supplied by the Novo Research Institute (NRI), closely following their recommended protocol. At the same time, samples of her blood were drawn and sent to the NRI for determination of IgE and IgG levels (Falholt, 1982).

The result of the intradermal skin tests (Table I) showed that she was indeed allergic to the porcine insulin. She was then switched to human insulin (Actrapid HM and Monotard HM, Novo) and no further reactions occurred. Her diabetes continued to be well controlled. At term, she went into spontaneous

P. K. Yap, M.B., B.S. (Malaya), M.R.C.P. (UK)

Accepted: 3 January 1985 labour, but the liquor was meconium stained, and a normal $3.4 \mathrm{~kg}$ baby boy was delivered by caesarian section. Post delivery, insulin was stopped and her diabetes was controlled by diet alone. Further IgE and IgG determinations were done after delivery (Table II).

\section{Discussion}

This patient is unusual because she is allergic to monocomponent porcine insulin, the least antigenic of the animal based insulins, though this has been reported before by Wiles et al. (1983). Primary reactions are even more unusual (Wishner \& Fisher, 1982) and the NRI has no record, to date, of any case of primary allergy to monocomponent porcine insulin.

The intradermal skin tests carried out on her showed that she was indeed highly allergic to porcine insulin. It is interesting to note that she also reacted to human insulin, though this reaction was of a short duration, and she did not develop similar lesions when on regular doses of human insulin. In the report by Kristensen \& Falholt (1983) on skin test reactions in 18 allergic patients, $45 \%$ showed no or minor reactions to human insulin as compared to bovine and porcine insulin, but $45 \%$ were also noted to react equally to the 3 types of insulin. Bruni et al. (1984) noted that the intradermal skin test to human insulin may still remain positive even after the allergic patient has been successfully switched to human insulin.

This patient's IgE levels against porcine insulin were markedly elevated, more so than against bovine and human insulin. Falholt et al. (1983) studying 23 insulin allergic patients found IgE binding greatest against bovine insulin, and least against human insulin with porcine insulin intermediate. This appears to correlate with the antigenicity of the 3 types of insulin. In this patient, the order was changed. This is a significant point, correlating well with her unusual allergy to monocomponent porcine insulin. 
Table I Results of intradermal skin testing on patient

\begin{tabular}{|c|c|c|c|c|c|}
\hline \multirow{2}{*}{ Preparation } & \multicolumn{5}{|c|}{ Time after injection } \\
\hline & $10 \mathrm{~min}$ & $30 \mathrm{~min}$ & $60 \mathrm{~min}$ & $120 \mathrm{~min}$ & $24 / 72 h$ \\
\hline Zinc acetate solution & \pm & \pm & - & - & _- \\
\hline Diluted Actrapid, human & $+\overline{+}+$ & ++ & + & - & _- \\
\hline Diluted Actrapid, porcine & ++++ & ++++ & +++ & ++ & subsided at $12 \mathrm{~h}$ \\
\hline Sodium chloride injection & - & - & - & - & - \\
\hline
\end{tabular}

There were no reactions to Actrapid and Monotard diluting medium.

Table II IgE and IgG anti-insulin antibody levels

\begin{tabular}{ccccl}
\hline $\begin{array}{c}\text { Porcine insulin } \\
\text { IgE U/ml }\end{array}$ & \multicolumn{2}{c}{ Bovine insulin } & Human insulin & \multicolumn{1}{c}{ Remarks } \\
IgE U/ml & IgG $U / m l$ & & \\
\hline 11.2 & 10.4 & 1.16 & 8.4 & Allergy skin testing \\
8.4 & 8.4 & 2.67 & 6.8 & On human insulin 1 month \\
2.3 & - & 0.28 & - & Off insulin 5 months \\
1.1 & - & 0.21 & - & Off insulin 11 months \\
\hline
\end{tabular}

Finally, the switch to human insulin was gratifying. There was immediate clinical improvement, and her IgE and IgG levels fell steadily. Since this patient was able to discontinue the insulin injections after delivery, we were presented with a unique opportunity to observe the rate of fall of her IgE and IgG levels. Fourteen months after she was switched to human insulin and 11 months after her delivery, her IgE level against porcine insulin had fallen almost to normal. This patient will continue to be followed up regularly, and subsequent pregnancies, if any, will afford a further opportunity to study her again.

\section{References}

BRUNI, B., CAMPANA, M., CARLINI, M., GAMBA ANSALDI, S., GRASSI, G., REGIS, G. \& TURCO, G.L. (1984). Treatment of allergy to bovine and porcine monocomponent insulin with human monocomponent insulin. Minerva Endocrinologica, 9, 173.

FALHOLT, K. (1982). Determination of insulin specific IgE in serum of diabetic patients by solid-phase radioimmunoassay. Diabetologia, 22, 254.

FALHOLT, K., HOSKAM, J.A.M., KARAMANOS, B.G., SUSSTRUNK, H., VISWANATHAN, M. \& HEDING, L.G. (1983). Insulin specific IgE in serum of 67 diabetic patients against

\section{Acknowledgements}

I wish to thank the local Novo agents for supplying the Insulin Allergy Testing Kit and the human insulin; the Novo Research Institute for measuring the IgE and IgG levels, and Dr J. Smedegaard Kristensen for his helpful advice at all times.

human insulin (Novo), porcine insulin and bovine insulin. Four case reports. Diabetes Care, 6, (Suppl.1), 61.

KRISTENSEN, J.S. \& FALHOLT, K. (1983). Human monocomponent insulin in the treatment of insulin allergic diabetics. Diabetes, 32, (Suppl.1), 66A.

WILES, P.G., GUY, R., WATKINS, S.M. \& REEVES, W.G. (1983). Allergy to purified bovine, porcine and human insulins. British Medical Journal, 286, 531.

WISHNER, K.L. \& FISHER, L.K. (1982). Insulin allergy in a 19 month old boy with newly diagnosed diabetes mellitus. Pediatrics, 70, 137. 